\title{
PARTICIPATIVE MANAGEMENT'S INFLUENCE ON EFFECTIVE STRATEGIC DIFFUSION
}

\author{
John A. Parnell \\ University of North Carolina at Pembroke \\ Pembroke, NC \\ Shawn Carraher \\ Texas A\&M University-Commerce \\ Commerce, TX
}

\author{
Kenneth Holt \\ Union University \\ Jackson, TN
}

\begin{abstract}
Recent research has highlighted the importance of middle and lower level managers in strategy formulation in ensuring that the strategy effectively "diffuses" throughout the organization. However, the question remains as to whether prevailing participative management styles in an organization can enhance this process. The present study suggests that the propensity of managers to employ participative management styles was found to positively influence the degree to which strategies were perceived as part of the organization.
\end{abstract}

\section{Introduction}

Strategic diffusion refers to the degree to which a strategy is effectively implemented and becomes an accepted part of the organization. Whereas much of the current research is based on the notion that strategy should "fit" with a variety of organizational and environmental constructs in order to lead to superior performance (e.g., Barney, 1986; Brouthers \& Arens, 1999; Hamilton \& Shergill, 1992; Neilsen, 1992; Zajac, Kraatz, \& Bresser, 2000), researchers have not fully considered behavioral factors in the organization that influence strategic diffusion. This paper considers whether or not the prevailing participative management styles in an organization influence top management's ability to "diffuse" the strategy throughout the organization.

\section{Strategic Diffusion}

Three dimensions of strategic diffusion - involvement, understanding, and commitment - have been elaborated in the literature (Parnell \& Crandall, 1995). The first dimension - involvement - concerns the degree to which middle and lower level managers were involved in the strategy-making process. 
Involvement can encompass numerous processes and techniques as long as it reflects top management's active consultation with other managers in the organization. Researchers have consistently found that individuals tend to work harder at attaining a goal when they were involved in setting it (Locke, Latham \& Erez, 1988; Roberson, Moye, \& Locke, 1999). Since strategy formulation encompasses some degree of implicit or explicit goal setting, greater involvement in formulation enhances efforts at implementation.

Although the concept of non-conceptual management involvement in strategy is not a recent phenomenon, the last decade has produced evidence to suggest that strategy formulation and implementation can reflect a diverse array of top and middle management inputs (Antonio, 1999; Barney, 1986; Burgelman, 1983; Currie, 1999; Thakur, 1998). Mintzberg and Waters' (1985) notion of deliberate and emergent strategies acknowledges the significant role of top and middle managers in the strategic management process. Paralleling the work of Burgelman (1983) and Hiam (1993), Nichol (1992) observed that top management simply cannot effectively develop a strategy and plan for its implementation without assistance from middle managers.

Wooldridge and Floyd (1990) conducted the most comprehensive empirical analysis of middle management strategic involvement. Not only did they find that middle management involvement in strategy formulation improved performance, they also noted that most organizations in the sample deliberately involved middle managers in the process. Although their study reflects a culmination of thought acknowledging involvement beyond the top manager and even the top management team (for example, see Barker \& Patterson, 1996; Schilit, 1987), most published studies utilizing perceptual data continued to rely solely on the perceptions of the top manager (Goll \& Johnson, 1996).

Wessel (1993) identified numerous individual barriers to effective implementation associated with management involvement, including conflicting managerial priorities, a top-down management approach (i.e., lack of non-conceptual manager involvement in strategy formulation), and poor communication. Others have focused on the need for "selling" the strategy to non-conceptual managers (Coulson-Thomas, 1992; Hambrick \& Cannella, 1989), but complete strategy permeation also may suggest non-conceptual manager involvement at the front end. The problem could be so acute that Brache (1992) even suggested that organizations consider adopting a system-oriented organizational structure to improve cross-functional communication, teamwork across functions, and a focus on system-wide goals instead of functional ones.

The second dimension - understanding - suggests that it is much easier to implement a strategy when middle and lower level managers thoroughly comprehend its component parts. Recent research has emphasized the need for a clear understanding of the organization's strategy among all managers in constructing the superior performing organization (Athanassiou \& Nigh, 2000; Meyer, 2000; Wright, Kroll, Pringle, \& Johnson, 1990). However, much of the strategy research in the 1970s and early 1980s followed Ansoff (1965) and 
others (Andrews (1971; Schendel \& Hofer, 1979), relying on the understanding of the top manager for insight into an organization's strategic intentions.

However, the belief that top management's clear understanding of strategy is all that matters is myopic. Strategic management helps organizations cope with uncertainty by helping shape the competitive environment (Das, Handfield, Calantone, \& Ghosh, 2000; Guth, 1976; Jauch \& Kraft, 1986; Katz, Zarzeski, \& Hall, 2000 ). The strategy selected by each organization determines the means by which it intends to successfully meet competitive challenges (Porter, 1980). Better information and certainty about the internal and external environments including competition - tends to translate into superior performance (Katz et al., 2000). If the management of uncertainty is the primary challenge of top management (Thompson, 1967), then effective implementation must reflect common perceptions of the strategy at all levels of management (Engdahl, Keating, \& Aupperle, 2000).

Understanding, however, is not sufficient. The third dimension - commitment - reflects the degree to which managers determine to see the strategy effectively implemented and become part of the organization. In the behavioral literature, commitment has been measured effectively through surveys. Theory and empirical research suggest a relationship between commitment and implementation (Locke et al., 1988). Whereas most of the emphasis on organizational commitment has been placed on gaining commitment to how things are done, little management emphasis has been focused on the issue of gaining commitment to what is done - the strategic dimension of the organization (Engdahl et al., 2000).

In sum, strategic diffusion is a function of management involvement in strategy development, management understanding of the strategy, and management's commitment to its effective implementation.

\section{The Propensity for Participative Management}

Research has suggested that the factors associated with strategic diffusion (i.e., involvement, understanding, commitment) tend to be enhanced through participative management styles (Yukl, 1989). However, not all managers possess the same desire to utilize participative management processes (Mudacumura, 2000). Parnell, Bell and Taylor (1992) identified three dimensions - organizational culture, organizational effectiveness, and power - that comprise a manager's propensity for employing participative management techniques. The first two are further examined in this study.

First, a manager's propensity for participative management is influenced by the prevailing culture of the organization. Individuals, as members of an organization, are likely to share common values, attitudes, and behaviors (Bennett, 1999; Oliver, 1999; Pettigrew, 1979). As such, managers in organizations where participation is prevalent are more likely to encourage their own subordinates to participate in decisions (Parnell et al., 1992). On the other hand, managers operating in organizations where decisions tend to be made autocratically are less likely to encourage their subordinates to participate. Thus, one's propensity 
for participative management may be affected by the degree to which such behavior is encouraged or discouraged by the organization.

Second, if a manager believes that participative decision making (PDM) enhances organizational effectiveness, he or she may be more likely to employ the technique. This belief may be reflected in the assertion that participation leads to higher quality decisions and greater productivity. Further, there may be a greater tendency to promote participation as a means of obtaining higher quality decisions when it is believed that subordinates prefer the added involvement. This notion has received considerable support in the literature.

In addition to quality, one's propensity for PDM (PPDM) is also influenced by a second factor - the perceived correlation between participation and productivity. In other words, a manager would likely employ PPDM if he or she believes that it will improve the productivity of the subordinates or the department as a whole. Indeed, much of the literature suggests a positive correlation between PDM and productivity (Dickson, 1982; Hennestad, 2000; Lovrich, 1985; Oradat, 1998). For example, Latham and Steele (1983) concluded that an acute positive relationship exists when participation involves the setting of employee goals. Likert and Araki (1986) proposed a "system five" consensus approach, citing the relationship between PDM and productivity. Lovrich (1985) investigated alleged participative management failures in the public sector and found little evidence to support the most typical managerial objections to participation. Managers who expect that PDM positively influences productivity are less likely to object to its utilization. Likewise, managers who believe that participation is an ethical imperative that improves organizational effectiveness tend to promote PDM with subordinates.

Participative decision making has been found to increase organizational effectiveness, improve relationships between managers and subordinates, increase creativity and productivity, increase company loyalty, and reduce absenteeism and turnover (Coch \& French, 1948; Tannanbaum \& Allport, 1956). Indeed, many have suggested that participation is the "right" or ethical approach to leadership (Latham \& Steele, 1983; Oradat, 1998; Weiss, 1998). However, there is no consensus on the universal effectiveness of participation (Kittrell \& Parnell, 1994). It appears to increase job performance and satisfaction in some situations but not in others. Some top managers have adopted and then abandoned this practice for various reasons, concluding the participation is not for their organizations. Research has examined possible reasons for the discontinuation of participative management: a lack of commitment or interest by management and employees, failure to properly implement the processes, and a lack of fit between the organization and the participative management processes.

\section{Hypotheses}

The present study tests four hypotheses associated with the PPDM components of organizational culture and decision effectiveness, and the strategic 
diffusion components of involvement and understanding. The hypothesized relationships are summarized in figure 1.

Figure 1

\section{Strategic Understanding Model}

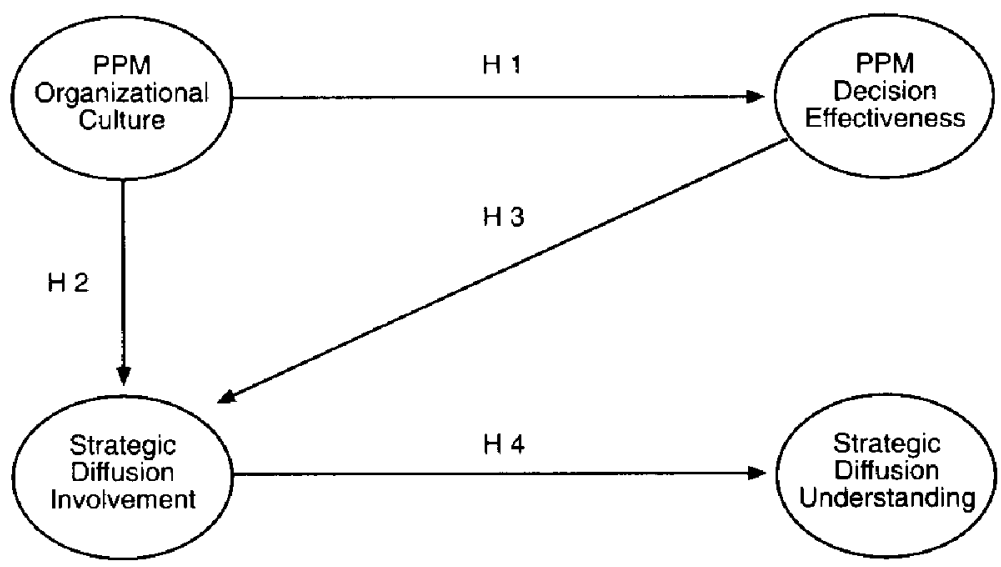

First, a positive linkage between a culture's participative nature and management beliefs that participation results in high quality decisions is expected. Individuals tend to believe that their own organizational culture - as they perceive it - is the "right one" (D'Andrade, 1984). Hence, if participation is an integral part of the organizational culture, then managers are more likely to support the idea that participative management will improve decision quality. Previous empirical research has demonstrated a positive relationship between these two dimensions of the PPM construct (Latham \& Steele, 1983).

Hypothesis 1: Managers in organizations with more participative cultures will be more likely to believe that participation improves the quality of decisions.

Second, it is believed that organizations that promote participative management styles are more likely to include managers beyond the top level in strategy formulation. This hypothesis is intuitively appealing, as it simply proposes that organizations that foster participation in routine managerial decisions are also likely to encourage participation in the strategy process.

Hypothesis 2: Managers in organizations with more participative cultures will tend to be more involved in strategy formulation.

Third, it is believed that managers who value participation the most are more likely to involve themselves in the decision of their superiors, including strategy formulation. In other words, if managers encourage their subordinates to participate in management decisions in part because they perceive a link 
between participation and effectiveness, one would expect these same managers to seek out opportunities to participate in the decisions that their managers make.

\section{Hypothesis 3: Managers who believe that participation en- hances decision quality will tend to be more involved in strat- egy formulation.}

Finally, it is suggested that those involved in formulating the organization's strategy will have the best understanding of it. Research has suggested a strong correlation between these two dimensions of the strategic diffusion construct (Schilit, 1987).

Hypothesis 4: Managers who are more involved in strategy formulation are more likely to possess a greater understanding of the implemented strategy.

\section{Development of the Strategic Diffusion Scale (SDS)}

\section{Item Selection}

In the first stage, items believed to reflect one of the three dimensions of strategic diffusion were developed, utilizing a seven-point Likert scale. A response of 7 denotes strong agreement (i.e., "strongly agree") with a given statement, while a response of 1 denotes strong disagreement (i.e., "strongly disagree"); responses of 2 through 6 were included to allow the participant to express moderate levels of agreement or disagreement with each item.

A 90-item initial survey of 107 practicing lower and middle managers suggested that 47 of the items were vague or conceptually inadequate in wording; these items did not justify further consideration. The surviving 43 items were then further scrutinized by the author and an additional management researcher in order to assess content validity. Twenty items were judged to be ambiguous, redundant, or not clearly reflective of the construct. These twenty items were eliminated; 23 remained for further testing.

A second survey consisting of the remaining 23 items was administered to 113 practicing lower and middle managers. An exploratory factor analysis and a scree test was applied and factor loadings were generated at what appeared to be a "natural cutoff" in eigenvalues $(7.40,2.63$, and 1.95). The resulting three factors accounted for 52.1 percent of the variance (Bollen, 1989). Eight items did not sufficiently load on one of the factors and were eliminated. A final theoretical scrutinization of the remaining items resulted in the elimination of two others in order to improve both parsimony and construct validity. The resulting instrument consisted of the strategic diffusion scale (SDS) as well as questions concerning age, gender, and managerial level.

The scale was then administered to 177 employees of eleven firms located in the Southeastern United States. Firms included both small entrepreneurial 
organizations and large multinational organizations with both the service sector and production sectors represented. The sample was 51 percent male and distributed almost evenly among lower [those managing workers] (47\%) and middle [those managing managers] (53\%) managerial levels. The ages of the respondents ranged from 22 to 68 with an average age of 37.1 .

The principal components (Harman \& Jones, 1966) factor extraction technique resulted in each item loading significantly on only one of the three factors. The loadings supported the existence of three dimensions of the construct. Eigenvalues were $6.26,1.56$, and 1.00 , with the three factors accounting for 67.9 percent of the variance. Hyperplane counts supported an oblique (oblimin) rotation method (Gorsuch, 1983). While other methods of rotation are available in factor analysis, this type of oblique rotation is preferable because of its ability to "obtain theoretically meaningful dimensions" (Kumar \& Beyerlein, 1991, p. 621). Table 1 lists the loadings of the three factors, along with their corresponding eigenvalues and percentage explained by each factor.

Table 1

Factor Loadings for the SDS

\begin{tabular}{|c|c|c|c|c|}
\hline Variable & Item Wording & $\begin{array}{c}\text { Factor } \\
\text { Loading }\end{array}$ & $\begin{array}{l}\text { Corrected } \\
\text { Item-Total } \\
\text { Correlation } \\
\end{array}$ & $\begin{array}{l}\text { Alpha } \\
\text { If Item } \\
\text { Deleted }\end{array}$ \\
\hline COM 1 & $\begin{array}{l}\text { I am committed to seeing that our organizational } \\
\text { strategy is effectively implemented }\end{array}$ & .836 & .784 & .894 \\
\hline $\operatorname{COM} 2$ & I don't worry about implementing strategy; I just do my job & .753 & .691 & .899 \\
\hline COM3 & $\begin{array}{l}\text { I don't concern myself with implementing } \\
\text { strategies if they are not beneficial to my department }\end{array}$ & .719 & .643 & .901 \\
\hline COM4 & $\begin{array}{l}\text { Departments in our company tend to be less concerned } \\
\text { with working together and more concerned with competing } \\
\text { for resources }\end{array}$ & .715 & .651 & 901 \\
\hline COM5 & $\begin{array}{l}\text { Our organization is most successful when } \\
\text { everyone works to implement a common strategy }\end{array}$ & .781 & .723 & .897 \\
\hline COM6 & Developing our company strategy is often a waste of time & .771 & .700 & .898 \\
\hline UNDI & $\begin{array}{l}\text { I fully understand the strategy my organization } \\
\text { is attempting to implement }\end{array}$ & .730 & .667 & .900 \\
\hline UND2 & $\begin{array}{l}\text { I know how our present strategy differs from } \\
\text { that which was developed last year }\end{array}$ & .610 & .546 & .905 \\
\hline UND3 & $\begin{array}{l}\text { Strategy is top management's problem } \\
\text { I don't have time to understand all of the details }\end{array}$ & .653 & .590 & .903 \\
\hline UND4 & I know where our company intends to be in five years & .671 & .606 & .902 \\
\hline INVI & $\begin{array}{l}\text { My superiors frequently ask for my input } \\
\text { concerning the direction of the company }\end{array}$ & .487 & .425 & .909 \\
\hline INV2 & $\begin{array}{l}\text { When strategic or policy decisions are handed } \\
\text { down to me, they often come as a surprise }\end{array}$ & .523 & .462 & .908 \\
\hline INV3 & $\begin{array}{l}\text { Our strategtes would be more effective if I had a } \\
\text { greater oppotunity to contribute my opinions }\end{array}$ & .686 & .624 & .902 \\
\hline
\end{tabular}


The first dimension (in the order of factor loadings) - understanding - is measured with four items. UND1 directly assesses the belief that the manager understands the organization's strategy. UND2 measures the extent to which the respondent can differentiate between the present strategy and the previous one. UND3 addresses the perception that understanding is not important at middle and lower management levels. UND4 concerns knowledge about strategy in a specified time frame.

The second dimension - involvement - is measured by three items. INV1 directly assesses the degree to which superiors ask for inputs into the strategy making process. INV2 concerns the degree to which strategies appear to reflect the input. INV3 (reverse coded) assesses one's beliefs concerning the value of his or her involvement in strategy formulation.

The third dimension - commitment - is measured with six items. COM1 directly assesses the commitment to effective implementation. COM2 (reverse coded) concerns the perception that strategy implementation is not a primary concern of the respondent. COM 3 (reverse coded) addresses the perception that some strategies may benefit some departments or members of the organization more than others. COM4 (reverse coded) addresses competitiveness among departments in the organization. COM5 concerns the need for cohesion in the organization. COM6 (reverse coded) addresses the perceived value of strategy formulation. The use of limited information factor analysis (Sethi \& Carraher, 1993) supported the unidimensionality of each of the scales.

Reliability and validity were assessed to ensure the integrity of the strategic diffusion scale. Coefficient alpha (Cronbach, 1951) for the SDS was .91, indicating that the scale has a high level of internal consistency, an important indication of reliability (Kuratko, Montagno \& Hornsby, 1990; Peter, 1979). Coefficient alphas for each of the subscales were .91 for the COM subscale, .84 for the UND subscale, and .67 for the INV subscale.

\section{Findings}

\section{The PPM Scale}

The principal components (Harman \& Jones, 1966) factor extraction technique resulted in each item loading significantly on only one of the three factors. The loadings supported the existence of three dimensions of the construct. Eigenvalues were $5.78,1.34$, and 0.78 , with three factors accounting for 65.9 percent of the variance. As supported by hyperplane counts, the data were rotated using an oblique (oblimin) rotation method. Table 2 provides factor loadings, coefficient alpha, and alphas following an item deletion routine.

The first dimension of the scale - culture - encompasses six items that measure the influence of norms and behaviors on PPM. PPMCUL1 and PPMCUL2 reflect culture at the department level, whereas PPMCUL3PPMCUL6 reflect culture at the organizational level. The second dimension organizational effectiveness - encompasses three items that consider one's 
beliefs concerning the relationship between participative management and the organizational variables of decision quality (PPMORG1 and PPMORG2) and interpersonal relationships (PPMORG3). The third dimension - power considers the perceived relationship between participation and the superior's power and control (PPMPWR1-PPMPWR3).

Reliability and validity were assessed to ensure the integrity of the PPM scale. Coefficient alpha (Cronbach, 1951) for the scale was 90 , indicating that the scale has a high level of internal consistency, an important indication of reliability (Kuratkoet al., 1990; Peter, 1979) and limited information factor analysis supported their unidimensionalities.

\section{Hypotheses}

Having established reliability of the two scales, it was necessary to develop measures for each of the elements in the model. To do so, each of the four subscales utilized in the study (i.e., two from the PPM scale and two from SDS scale) were factor analyzed separately and factor scores (regression method) were computed to serve as composite measures of each dimension. Table 3 provides the factor loadings and coefficient alphas for each analysis. Table 4 provides correlations and significance levels among each of these factors.

Table 2

\section{Factor Loadings for the PPM Scale}

\begin{tabular}{|c|c|c|c|c|}
\hline Variable & Item Wording & $\begin{array}{c}\text { Factor } \\
\text { Loading }\end{array}$ & $\begin{array}{l}\text { Corrected } \\
\text { Item-Total } \\
\text { Correlation } \\
\end{array}$ & $\begin{array}{c}\text { Alpha } \\
\text { if Item } \\
\text { Deleted } \\
\end{array}$ \\
\hline PPMCULI & $\begin{array}{l}\text { My subordinates tend to possess the same } \\
\text { organizational goals I have }\end{array}$ & .746 & .688 & .887 \\
\hline PPMCUL2 & My subordinates are generally informed and experienced & .762 & .689 & .888 \\
\hline PPMCUL3 & $\begin{array}{l}\text { Participative decision making is widely used in } \\
\text { my organization }\end{array}$ & .723 & .649 & .889 \\
\hline PPMCULA & I am free to make decisions as I wish in my organization & .640 & .557 & .894 \\
\hline PPMCUL5 & Participative decision making is promoted in my organization & on .681 & .598 & .892 \\
\hline PPMCUL6 & $\begin{array}{l}\text { My boss frequently solicits my participation } \\
\text { in his or her decisions }\end{array}$ & .711 & .634 & .890 \\
\hline PPMORG1 & $\begin{array}{l}\text { Many organizational problems disappear when everyone } \\
\text { has a chance to participate in decision making }\end{array}$ & .726 & .656 & .889 \\
\hline PPMORG2 & $\begin{array}{l}\text { Participative decision making usually results } \\
\text { in effective decisions }\end{array}$ & .774 & .713 & .886 \\
\hline PPMORG3 & $\begin{array}{l}\text { Participative decision making promotes positive } \\
\text { relationships at all levels of the organization }\end{array}$ & .762 & .687 & .887 \\
\hline PPMPWR 1 & $\begin{array}{l}\text { Participative decision making requires divulging } \\
\text { too much confidential information }\end{array}$ & .559 & .502 & .896 \\
\hline PPMPWR2 & $\begin{array}{l}\text { Participative decision making gives too much } \\
\text { power to subordinates }\end{array}$ & .580 & .523 & .895 \\
\hline PPMPWR3 & Subordinates often cannot be trusted & .593 & .531 & .896 \\
\hline
\end{tabular}


Correlational analysis lent support to each of the four hypotheses. First, the correlation between the PPM dimensions of organizational culture and decision effectiveness was .52. Second, the correlation between the PPM dimension of organizational culture and the strategic diffusion dimension of involvement was 41 . Third, the correlation between the PPM dimension of decision effectiveness and the strategic diffusion dimension of involvement was .35. Finally, the correlation between the strategic diffusion dimensions of involvement and understanding was . 56 .

\section{Structural Equation Model}

A structural equation model was developed to test the four hypotheses simultaneously (see figure 2). For the PPM factors (i.e., organizational culture and decision effectiveness), the best three measures were retained; for the strategic diffusion factors (i.e., involvement and understanding), the best two measures were retained. Saturated models with all construct measures were tested but were rejected because of high covariances among measurement errors across constructs.

Table 3

Factor Loadings for Single-Factor Solutions

\begin{tabular}{lc}
\hline Item & Factor Loading \\
\hline Strategic Diffusion- Involvement (alpha $=.67$ ) & \\
INV1 & .685 \\
INV2 & .817 \\
INV3 & .832 \\
Strategic Diffusion-Understanding (alpha $=.84$ ) & \\
UND1 & .828 \\
UND2 & .814 \\
UND3 & .789 \\
UND4 & .842 \\
Strategic Diffusion-Commitment (alpha $=.91$ ) & \\
COM1 & .836 \\
COM2 & .789 \\
COM3 & .844 \\
COM4 & .774 \\
COM5 & .849 \\
COM6 & .860 \\
PPM-Organizational Culture (alpha=.86) & \\
PPMCUL1 & .793 \\
PPMCUL2 & .816 \\
PPMCUL3 & .768 \\
PPMCUL4 & .682 \\
PPMCUL5 & .764 \\
PPMCUL6 & .753 \\
PPM-Decision Effectiveness (alpha $=.81)$ & \\
PPMORG1 & .823 \\
PPMORG2 & .863 \\
PPMORG3 & .864 \\
\hline
\end{tabular}


The chi-square statistic was 40.642 ( $\mathrm{df}=31$ ), with a probability level of .115. The chi-square is the most widely accepted overall measure of fit for a structural equation model. However, three additional measures warrant consideration (Arbuckle, 1997). First, the Bentler-Bonett (1980) normed fit index (NFI) compares the proposed model to a baseline model. Bentler and Bonett (1980) suggested that NFI statistics above .90 suggest that the model cannot be improved substantially. The NFI for the proposed model was .989 .

\section{Table 4}

\section{Correlations}

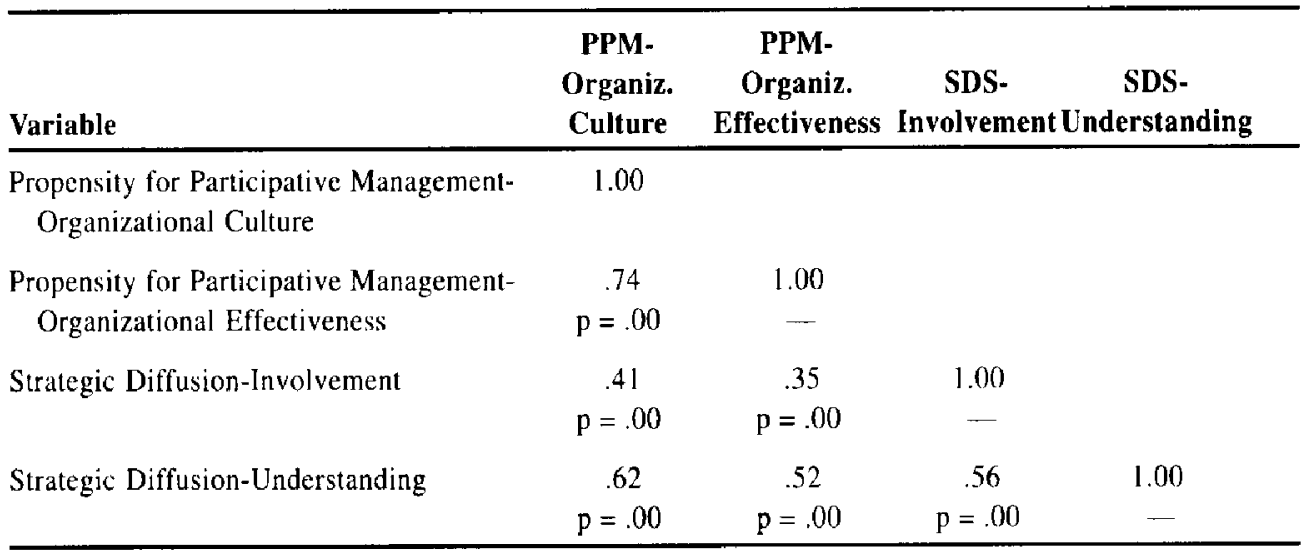

Figure 2

Structural Equation Model

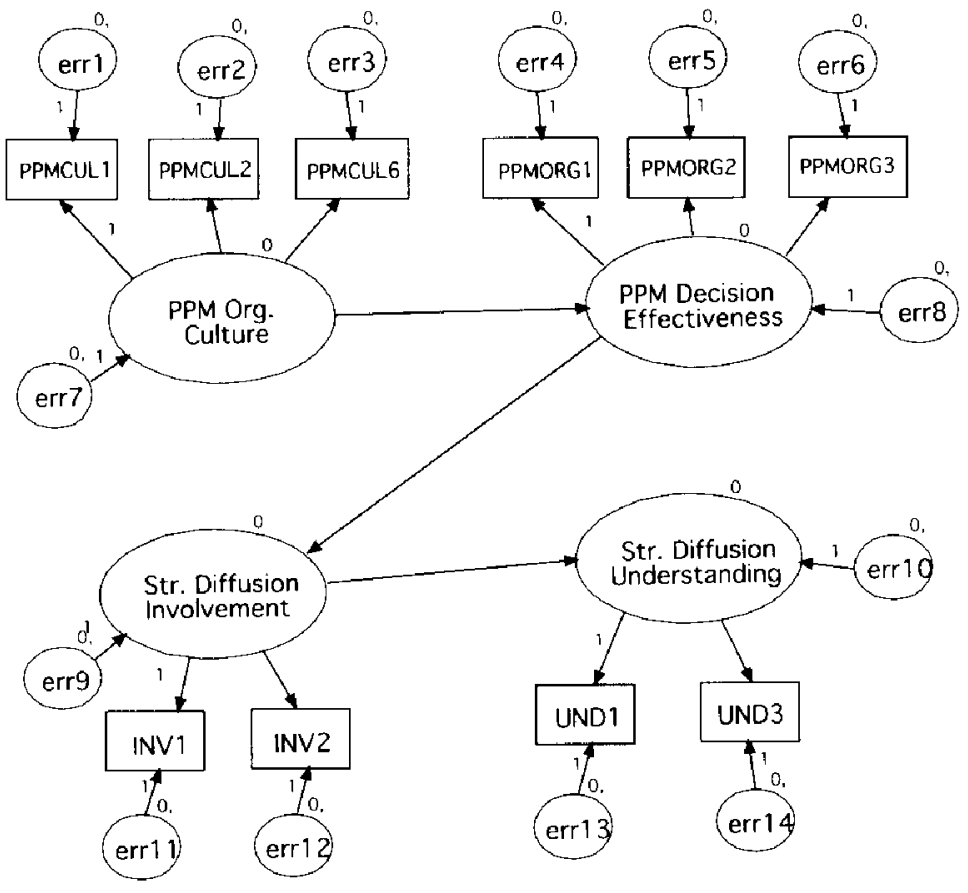


Second, the comparative fit index (CFI) also compares the proposed model to a baseline model (Bentler, 1980). Scores in the .90 or .95 range or higher suggest that it would be difficult to substantially improve the model fit. The CFI for the proposed model was .997.

Finally, the "root mean square error of approximation" (RMSEA) statistic attempts to overcome the bias of chi-square by compensating for model complexity. Browne and Cudeck (1993) suggested that values of .08 or less represent reasonable errors or approximation, whereas values greater than .10 represent unreasonable errors. The RMSEA for the proposed model was .042. Path estimates appear in table 5 .

Table 5

Path Estimates for Structural Equation Model

\begin{tabular}{lcc}
\hline Path & Path Estimate & Standard Error \\
\hline PPM Decision Effectiveness - PPM Organizational Culture & 0.674 & 0.081 \\
Str. Diffusion Involvement - PPM Organizational Culture & 0.306 & 0.129 \\
Str. Diffusion Involvement - PPM Dec. Effectiveness & 0.087 & 0.151 \\
Str. Diffusion Understanding - Str. Diffusion Involvement & 1.562 & 0.340 \\
PPMCUL1 - PPM Organizational Culture & 1.000 & \\
PPMCUL2 - PPM Organizational Culture & 0.748 & 0.075 \\
INV1 - Str. Diffusion Involvement & 1.000 & \\
INV2 - Str. Diffusion Involvement & 1.131 & 0.252 \\
PPMORG1 - PPM Decision Effectiveness & 1.000 & \\
PPMORG3 - PPM Decision Effectiveness & 1.344 & 0.141 \\
UND1 - Str. Diffusion Understanding & 1.000 & \\
UND3 - Str. Diffusion Understanding & 1.190 & 0.161 \\
PPMCUL6 - PPM Organizational Culture & 0.844 & 0.089 \\
PPMORG2 - PPM Decision Effectiveness & 1.156 & 0.127 \\
\hline
\end{tabular}

Within the model, proposed linkages among the constructs were strong, with the exception of the link between PPM decision effectiveness and strategic diffusion involvement. The model was modified to remove the link, but comparisons between the two competing models were inconclusive. In sum, the structural equation model lends strong support for the first, second, and fourth hypotheses, and limited support for the third hypothesis.

\section{Discussion, Conclusions, and Future Research}

This paper considered factors in the organization that may influence strategic diffusion. It specifically explored the role that managers' propensity for 
participative management styles might play in the effective diffusion of strategy throughout the organization. The support found for the second and fourth hypotheses particularly indicate that a participative organizational culture breeds more involvement in the formulation of strategy and that managers who are more involved in strategy formulation have a greater understanding of the implemented strategy.

The lack of support found for the third hypothesis in the structural equation model may be interpreted as implying that managers who believe that participation enhances decision quality will not tend to be more involved in strategy formulation. Instead it may be that the stated hypothesis is true, except that the nature of the culture may modify the relationship. A manager may very well agree that participation enhances decision quality and may prefer more involvement in strategy formulation, but if that belief is not accompanied by a participative culture that affords the manager an opportunity to become involved, his or her involvement in strategy formulation may be limited.

These findings represent an important first step in the process of examining the organizational factors that may influence the diffusion of strategy. They also create an important bridge between organizational theory, organizational behavior, and strategic management. Despite great efforts of management to develop an effective strategy for the organization, without the means to share the strategy throughout the organization its potential successes may not be realized (Engdahl et al., 2000).

Two future research directions have been identified. First, the SDS does not take into account organization-specific factors that may affect strategic diffusion and ultimately be associated with PPM. Research must inevitably probe more deeply into the impact of organizational culture on the strategy making process (Athanassiou \& Nigh, 2000; Harris \& Purdy, 1998). Strategic change challenges the taken-for-granted beliefs of all organizational members and typically is not easy to accomplish (Scholes, 1991). For instance, Hennestad (2000) examined attempts for Extrusion Company to transform itself from a traditional style of management to a participative style of management and he reported that insufficient attention was paid to the change management process which led to a lack of momentum for the change process. Earlier, Lorenz (1988) demonstrated that General Electric was not able to defend its market positions in many of eighteen businesses studied because sudden changes of any kind tended to be perceived as evidence of poor and inadequate planning rather than as an indication of the volatility of the real world. As a result, GE increased the involvement of line managers in the strategy process and was thus able to better defend its market positions. Longitudinal research designs could be especially effective in answering questions such as whether an organizational culture that values PPM leads to greater strategic understanding, and then whether this understanding influences actual organizational performance (Oliver, 1999) and it also may prove fruitful for future research to examine and compare the results across countries both within a single organization and across organizations. 
Second, the results of this study implore researchers to more fully integrate behavioral theory into the equation by determining what may lead to strategic diffusion. Specifically, an examination of the processes through which top managers involve subordinates in the strategy making process may provide insight into the genesis of strategic consensus. The intricacies surrounding one specific form of participative management - participation in strategy making and its relationship to strategic consensus - remain tenuous (Crandall \& Parnell, 1994). In addition, factors such as personality, cognitive complexity, managerial diversity, experience, and functional background (Carraher \& Buckley, 1996; Carraher \& Whitely, 1998) may provide insight into why some strategies are more easily diffused than others (Budd \& Carraher, 1998). Indeed, this avenue holds the potential for increased dialogue among various managerial disciplines.

In sum, this study has demonstrated a linkage between propensity for participative management and strategic diffusion. Results suggest that perceptions of greater participation may result in more effective dissemination of the organization's strategy and greater decision effectiveness.

\section{References}

Andrews, K. (1971). The concept of corporate strategy. Homewood, IL: Dow Jones.

Ansoff. H.I. (1965). Corporate strategy: An analytical approach to business policy for growth and expansion. New York: McGraw-Hill.

Antonio, D. (1999). What motivates middle managers. Industrial Management, 41(6), $27-30$.

Arbuckle, J.L. (1997). AMOS user's guide version 3.6. Chicago, IL: Smallwaters Corporation.

Athanassiou, N., \& Nigh, D. (2000). Internationalization, tacit knowledge and the top management teams of MNCs. Journal of International Business Studies, 31(3), 471487

Barker, V.L., \& Patterson, P.W., Jr. (1996) Top management team tenure and top manager causal attributions at declining firms attempting turnarounds. Group and Organization Management, 21(3), 304-336.

Barney, J.B. (1986). Types of competition and the theory of strategy: Toward an integrative framework. Academy of Management Review, 11, 791-800.

Bennett, R.H., III. (1999). The relative effects of situational practices and culturally influenced values/beliefs on work attitudes. International Journal of Commerce and Management, 9(1/2), 84-102.

Bentler, P.M. (1980). Multivariate analysis with latent variables: Causal modeling. Annual Review of Psychology, 31, 419-456. 
Bentler, P.M. \& Bonett, D.G. (1980). Significance tests and goodness of fit in the analysis of covariance structures. Psychological Bulletin, 88, 588-606.

Bollen, K.A. (1989). Structural equations with latent variables. New York: John Wiley \& Sons.

Brache, A.P. (1992). Process improvement and management: A Tool for strategy implementation. Planning Review, 20, 5, 24-26.

Brouthers, K.D., \& Arens, P. (1999). Privatization and strategic fit: Evidence from Rumania. Business Strategy Review, 10(2), 53-59.

Browne, M.W., \& Cudeck, R. (1993). Alternative ways of assessing model fit. In Bollen, K.A. \& Long, J.S. (Eds.) Testing Structual Equation Models. Newbury Park, CA: Sage Publications, pp. 136-162.

Budd, J. \& Carraher, S. (1998). Validation of an inventory to measure attributes of strategic management. Psychological Reports, 82, 1220-1222.

Burgelman, R.A. (1983). A model of the interaction of strategic behavior, corporate context, and the concept of strategy. Academy of Management Review, 8, 61-70.

Carraher, S. \& Buckley, M.R. (1996). The effect of cognitive complexity on the perceived dimensionality of the PSQ. Journal of Applied Psychology, 81, 102-109.

Carraher, S. \& Whitely, W. (1998). Motivations for work and their influence on pay across six countries. Global Business and Finance Review, 3, 49-56.

Coch, L., \& French, J.R.P., Jr. (1948). Overcoming resistance to change, Human Relations, $1,512-532$.

Coulson-Thomas, C. (1992). Leadership and corporate transformation. Leadership and Organization Development Journal, 13, 16-27.

Crandall, W.R., \& Parnell, J.A. (1994). On the relationship between propensity for participative management and intentions to leave: Re-opening the case for participation. Mid-Atlantic Journal of Business, 30, 197-209.

Cronbach, L.J. (1951). Coefficient alpha and the internal structure of tests. Psychometrica, 16, 297-334.

Currie, G. (1999). The influence of middle managers in the business planning process: A case study in the UK NHS. British Journal of Management, 10(2). 141-155.

D'Andrade, R. (1984). Cultural meaning systems. In Culture Theory, R. Shweder \& R. Levine (eds.), pp. 88-119. 
Das, A., Handfield, R.B., Calantone, R.J., \& Ghosh, S. (2000). A contingent view of quality management - The impact of international competition on quality. Decision Sciences, 31(3), 649-690.

Dickson, J.W. (1982). Top managers' beliefs and rationales for employee participation. Human Relations, 35(3), 203-217.

Engdahl, R.A., Keating, R.J., \& Aupperle, K.E. (2000). Strategy and structure: Chicken or egg? (Reconsideration of Chandler's paradigm for economic success). Organizational Development Journal, 18(4), 21-33.

Goll, I., \& Johnson, N.B., (1996). The role of top management demographic characteristics in employee participation programs. International Journal of Management, $13(1), 76-83$.

Gorsuch, R. (1983). Factor Analysis (2nd Ed.) Hillsdale. NJ: Lawrence Erlbaum Associates Publishing.

Guth, W. (1976). Toward a social system theory of corporate strategy. Journal of Business, $49,374-388$.

Hambrick, D.C., \& Cannella, A.A., Jr. (1989). Strategy implementation as substance and selling. Academy of Management Executive, 3, 278-285.

Hamilton, R.T., \& Shergill, G.S. (1992). The relationship between strategy-structure fit and financial performance in New Zealand: Evidence of generality and validity with enhanced controls. Journal of Management Studies, 29(1), 95-113.

Harman, H.H., \& Jones, W.H. (1966). Factor analysis by minimizing residuals. Psychometrica, 31, 351-368.

Harris, C.R., \& Purdy, R.L. (1998). The role of participative management in the implementation of total quality management programs. International Journal of Technology Management, 16(4-6), 466-478.

Hennestad, B.W. (2000). Implementing participative management: Transition issues from the field. Journal of Applied Behavior Science, 36(3). 314-335.

Hiam, A. (1993). Strategic planning unbound. Journal of Business Strategy, 14(2), 4652.

Jauch, L.R., \& Kraft, K.L. (1986). Strategic management of uncertainty. Academy of Management Review, 11, 777-790.

Katz, J.P., Zarzeski, M.T., \& Hall, H.J. (2000) The impact of strategy, industry, and culture on forecasting the performance of global competitors: A strategic perspective. Journal of Business Strategies, 17(2), 119-143. 
Kittrell, L.M., \& Parnell, J.A. (1994). An analysis of the relationship between organizational character and propensity for participative management. Proceedings of the Annual Meeting of the lnstitute of Behavioral and Applied Management, Washington, DC.

Kumar, K., \& Beyerlein, M. (1991). Construction and validation of an instrument for measuring ingratiatory behaviors in organizational settings. Journal of Applied Psychology, 76, 619-627.

Kuratko, D.F., Montagno, R.V., \& Hornsby, J.S. (1990). Developing an intrapreneurial assessment instrument for an effective corporate entrepreneurial environment. Strategic Management Journal, 11, 49-58.

Latham, G.P. \& Steele, T.P. (1983). The motivational effects of participation versus goal setting on performance. Academy of Management Journal, 26(3), 406-17.

Likert, J.G., \& Araki, C.T. (1986). Managing without a boss: System five. Leadership and Organization Development Journal, 7(3), 17-20

Locke, E.A., Latham, G.P., \& Erez, M. (1988). The determinants of goal commitment. Academy of Management Review, 13, 23-39.

Lorenz, C. (1988, May 18). Why strategy has been put in the hands of line managers. Financial Times, p. 20.

Lovrich, N.P. (1985). The dangers of participative management: A test of unexamined assumptions concerning employee involvement. Review of Public Personnel Administration, 5(3), 9-25.

Meyer, H. (2000). Boards take on the heavy lifting. Journal of Business Strategy, 21(4), 18-23.

Mintzberg, H. \& Waters, J.A. (1985). Of strategies, deliberate and emergent. Strategic Management Journal, 6, 257-272.

Mudacumura, G.M. (2000). Participative management in global transformational change. International Journal of Public Administration, 23(12), 2051-2083.

Neilsen, A. (1992). A New metaphor for strategic fit: All that jazz. Leadership and Organization Development Journal, 13(5), 3-6.

Nichol, R.L. (1992). Get middle managers involved in the planning process. Journal of Business Strategy, 13(3), 26-32.

Oliver, B.L. (1999). Comparing corporate managers' personal values over three decades. Journal of Business Ethics, 20(2), 147-161. 
Oradat, G.D. (1998). A supervisor's responsibility in a gainsharing and continuous improvement environment. Supervision, 59(5). 3-4.

Parnell, J.A., Bell, E.D., \& Taylor, R. (1992). The propensity for participative management: A conceptual and empirical analysis. Mid-Atlantic Journal of Business. $28(1), 31-42$.

Parnell, J.A., \& Crandall, W.R. (1995). The strategic diffusion construct: Measuring a strategy's dissemination throughout the organization. Proceedings of the 1995 Southeast TIMS Meeting, Myrtle Beach, SC.

Peter, J.P. (1979). Reliability: A review of psychometric basics and recent marketing practices. Journal of Marketing Research, 16, 6-17.

Pettigrew, A.M. (1979). On studying organizational cultures. Administrative Science Quarterly, 24, 570-581.

Porter, M.E. (1980). Competitive strategy. New York: Free Press.

Roberson, Q.M., Moye, N.A., \& Locke, E.A. (1999). Identifying a missing link between participation and satisfaction: The mediating role of procedural justice perceptions. Journal of Applied Psychology, 84(4), 585-593.

Schendel, D., \& Hofer, C. (1979). Strategic Management. Boston, MA: Little, Brown.

Schilit, W.K. (1987). An examination of the influence of middle-level managers in formulating and implementing strategic decisions. Journal of Management Studies, $24,271-293$.

Scholes, K. (1991). The way to manage strategic change. Accountancy, 107(1170), 9899.

Sethi, V. \& Carraher, S. (1993). Developing measures for assessing the organizational impact of information technology: A comment on Mahood and Soon's paper. Decision Sciences, 24, 867-877.

Tannenbaum, A.S., \& Allport, F.H. (1956). Personality structure and group structure; An interpretive study of their relationship through an event structure hypothesis. Journal of Abnormal and Social Psychology, 53, 272-280.

Thakur, M. (1998). Involving middle managers in strategy making. Long Range Planning, 31(5), 732-741.

Thompson, J.D. (1967). Organizations in Action. New York: McGraw-Hill.

Weiss, W.H. (1998). Improving employee performance: Major supervisory responsibility. Supervision, 59(10), 6-8. 
Wessel, J.R. (1993). The strategic human resource management process in practice. Planning Review, 21, 5, 37-38.

Wooldridge, B., \& Floyd, S.W. (1990). The strategy process, middle management involvement, and organizational performance. Strategic Management Journal, 11, 231-241.

Wright, P., Kroll, M., Pringle, C., \& Johnson, J. (1990). Organization types, conduct, profitability and risk in the semiconductor industry. Journal of Management Systems, 2(2), 33-48.

Yukl, G. (1989). Managerial leadership: a review of theory and research. Journal of Management, 15(2), 251-289.

Zajac, E.J., Kraatz, M.S., \& Bresser, R.K.F. (2000). Modeling the dynamics of strategic fit: A normative approach to strategic change. Strategic Management Journal, 21(4), 429-453.

John A. Parnell (john_parnell@tamu-commerce.edu) earned the Doctor of Philosophy degree in Strategic Management from the University of Memphis. Dr. Parnell presently serves as the William Henry Belk Distinguished Professor of Management at the University of North Carolina at Pembroke. He is the author of over 100 basic and applied research articles, published presentations, and cases. His present research is focused on business strategy and performance, subordinate participation, and management ethics.

Shawn Carraher (shawn_carraher@tamu-commerce.edu) received his Ph. D. in Business Administration from the University of Oklahoma. He presently serves as Professor of Management \& Global Entrepreneurship at Texas A\&M University-Commerce. His primary research interests combine international business, strategic management, human resources, and entrepreneurship in order to examine cross-cultural differences in compensation, selection, and staffing within entrepreneurial organizations.

M. Kenneth Holt (kholt@uu.edu) received the M.S. degree from Louisiana State University and is presently a Ph.D. candidate at the University of Memphis. He also serves as an Associate Professor of Economics and Management and Director of the Center for Business \& Economic Development at Union University.

\section{Footnotes}

' This paper is not concerned with which means of involvement are more or less effective, but rather with the perception by middle and lower level managers of the degree to which they were involved in the strategy formulation process. 